\title{
Effect of Antimicrobial Myrrh on the Color and Viscosity of Plain Yogurt over Its Shelf Life
}

\author{
Mohammed Alhejaili, Douglas Olson, Kayanush Aryana* \\ School of Nutrition and Food Sciences, Louisiana State University Agricultural Center, Baton Rouge, LA, USA \\ Email: *karyana@agcenter.lsu.edu
}

How to cite this paper: Alhejaili, M., Olson, D. and Aryana, K. (2019) Effect of Antimicrobial Myrrh on the Color and Viscosity of Plain Yogurt over Its Shelf Life. Food and Nutrition Sciences, 10, 1236-1242. https://doi.org/10.4236/fns.2019.1010089

Received: September 17, 2019

Accepted: October 27, 2019

Published: October 30, 2019

Copyright $\odot 2019$ by author(s) and Scientific Research Publishing Inc. This work is licensed under the Creative Commons Attribution International License (CC BY 4.0).

http://creativecommons.org/licenses/by/4.0/

\begin{abstract}
Myrrh, commercially available as a brown powder, is a natural flavoring substance approved for food use by US Food and Drug Administration and has antibacterial and antifungal activity against pathogens. The objective was to determine the effect of myrrh on the color $\left(L^{*}, a^{*}, b^{*}, C^{*}, h^{*}\right)$ and viscosity of yogurt over refrigerated storage. Myrrh dispersion was prepared and incorporated at a $1 \% \mathrm{v} / \mathrm{v}$ level into yogurt. A control with no myrrh was also prepared. Three replications were conducted. At a usage level of $1 \% \mathrm{v} / \mathrm{v}$, myrrh influenced the color attributes $\mathrm{L}^{*}, \mathrm{a}^{*}$ and $\mathrm{h}^{*}$ but did not influence the viscosity of the plain yogurts.
\end{abstract}

\section{Keywords}

Antimicrobial, Fermented, Myrrh

\section{Introduction}

Myrrh is extracted from Commiphora trees of the Burseraceae family (Commiphora species are small trees or shrubs with short, thorny branches). Commiphora myrrha is a variable species found in southern Arabia and northeast Africa as far south as northeast Kenya. Genus Commiphora comprises more than 200 species [1]. Myrrh is composed of essential oil (2\% - 10\%), ethanol-soluble resin $(25 \%-40 \%)$, and water-soluble gum (30\% - 60\%) [1].

Extracts from many types of plants have been used as flavoring and seasoning agents in foods and beverages and also as folk medicines and food preservatives since ancient time. Myrrh is a safe, natural flavoring substance approved by the US Food and Drug Administration [2]. It adds characteristic flavor and prolongs the shelf life of foods by their antioxidant, bacteriostatic, and bactericidal activity [3]. Myrrh has considerable antibacterial and anti-fungal activity [2] and is used to cure variety of diseases. Myrrh alongside with honey and bee propolis can 
help to cure chronic non-healing wounds such as diabetic foot disease [2]. The traditional way of taking myrrh as a medicine to treat sore throat and a cold was by adding $4 \mathrm{oz}$. (113 g) of boiled water to a third teaspoon $(1.67 \mathrm{~mL})$ of myrrh. This was followed by consuming a teaspoon $(1.67 \mathrm{~mL})$ of myrrh dispersion every day.

Myrrh is commercially available as a brown powder. To our knowledge, there has not been much research performed on myrrh in foods. Myrrh could play a role in safer and increased shelf life yogurts. Whether myrrh has color and viscosity altering effects on yogurt are not known. The objective of this research was to study the effect of myrrh on the color and viscosity of yogurt over its shelf life.

\section{Materials and Methods}

\subsection{Preparation of the Myrrh}

The myrrh powder (Embalee Mond Trading Company, West Toronto, Ontario, Canada) was dissolved in boiling distilled water to make $10 \%(\mathrm{w} / \mathrm{v})$ dispersion. The suspension of myrrh was set for an hour at room temperature to cool down. The suspension was centrifuged $\left(3677 \mathrm{~g}, 5 \mathrm{mins}, 20^{\circ} \mathrm{C}\right.$; Centrifuge, Fisher Scientific Accuspin 400, Osterode, Germany). Myrrh is composed of $97 \%$ insoluble matter that remained at the bottom of the tube and $3 \%$ soluble in the supernatant which was used. Myrrh supernatant was diluted to make 1\% (v/v) dispersion to mimic traditional medicinal use concentrations. The control had no myrrh.

\subsection{Preparation of Yogurt}

Yogurts were manufactured at the Louisiana State University creamery. Whole milk ( $7.57 \mathrm{~L}$ ) was heated to $85^{\circ} \mathrm{C}$ and held for 30 mins, followed by lowering the temperature to $41^{\circ} \mathrm{C}$. Warm milk was inoculated with $2 \mathrm{~mL}$ each of freshly thawed pure cultures of Streptococcus thermophilus ST-M5 and Lactobaciulls bulgaricus LB-12 (Chr. Hansen, Milwaukee, WI) respectively at $0.03 \%(\mathrm{v} / \mathrm{v})$. This was followed by adding $0 \%$ (control) and $1 \%(\mathrm{v} / \mathrm{v}$ ) of myrrh dispersion with agitation. After mixing, yogurt mixes were poured into $355 \mathrm{ml}$ Reynolds RDC212-Del-Pak Combo-Pak containers (Alcoa, Inc., Pittsburgh, PA, USA) and incubated at $40^{\circ} \mathrm{C}$ to $\mathrm{pH} 4.6$ before cooling to $4^{\circ} \mathrm{C}$. Control yogurt had no myrrh. Yogurts were manufactured in triplicate.

\subsection{Color Measurements}

The $\mathrm{L}^{\star}$ (whiteness to blackness), $\mathrm{a}^{\star}$ (redness to greenness), $\mathrm{b}^{\star}$ (yellowness to blueness), $\mathrm{C}^{\star}$ (chroma) and $\mathrm{h}^{\star}$ (hue angle) values of the yogurts were determined with a HunterLab MiniScan XE Plus spectrophotometer (HunterLab, Reston, VA, USA) using Universal software (HunterLab, Reston, VA, USA). The spectrophotometer was calibrated with white and black tiles and used at D65 illuminant and $10^{\circ}$ observer. Five measurements were taken and averaged for 
each sample at approximately $5^{\circ} \mathrm{C} \pm 1^{\circ} \mathrm{C}$. Color measurements were obtained at $1,2,3,4$, and 5 weeks of storage.

\subsection{Apparent Viscosity}

The apparent viscosity of the yogurts was measured using a viscometer (Brookfield model DV-II+ with Helipath) (Brookfield Engineering Laboratories Inc., Stoughton, MA) according to [4] with some modifications. Temperatures of yogurts measured were $5^{\circ} \mathrm{C} \pm 1^{\circ} \mathrm{C}$. A T-C spindle was used at $30 \mathrm{rpm}$. Data points were acquired using the Wingather 32 software (Brookfield Engineering Laboratories Inc.) and 100 data points were averaged per replication. Three replications were conducted.

\subsection{Statistical Analysis}

Data were analyzed as a randomized block design with repeated measures using Proc GLM of SAS (version 9.4, SAS Institute Inc., Cary, NC). Differences of least squares means were used to determine significant differences at $P<0.05$ for main effects (myrrh and storage time) and the interaction effect (myrrh ${ }^{*}$ storage time).

\section{Results and Discussion}

\subsection{Color}

\subsubsection{L* (Lightness to Darkness)}

The $\mathrm{L}^{*}$ values of the myrrh and control yogurts throughout 5 wks of storage are shown in Figure 1. The time effect and the interaction effect (myrrh ${ }^{\star}$ time) was not significant, but the treatment myrrh effect was significant (Table 1) and (Table 2). The $\mathrm{L}^{\star}$ of control yogurt remained steady throughout the 5 wks while the $L^{*}$ of myrrh yogurt increased by about 2 units throughout the 5 wks storage. The lightness of the control yogurt when it was fresh and throughout 5 wks of storage was higher than myrrh yogurts. The lightness of myrrh treatment slightly increased which may be because of the degradation of myrrh dispersion throughout $5 \mathrm{wks}$ storage time. According to [5] who incorporated myrrh essential oils into cheese reported that the control cheeses with

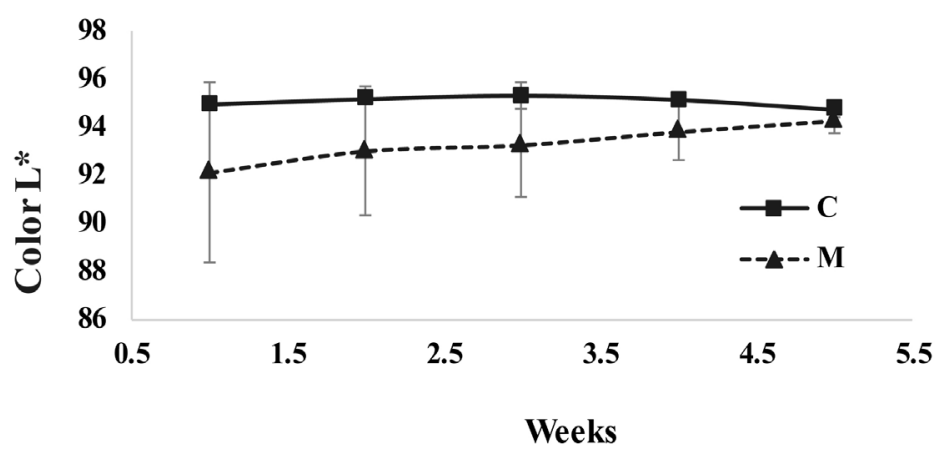

Figure 1. Measurement of $L^{\star}$ color for yogurts containing myrrh and control during storage time for 5 wks. 
Table 1. The $P$-values for myrrh, time and interactions for the colors of yogurts containing myrrh and control.

\begin{tabular}{cccccc}
\hline Effect & $\mathrm{L}^{*}$ & $\mathrm{a}^{*}$ & $\mathrm{~b}^{*}$ & $\mathrm{C}^{*}$ & $\mathrm{~h}^{*}$ \\
\hline Myrrh & 0.0032 & 0.0001 & 0.3505 & 0.4662 & 0.0034 \\
Time & 0.7631 & 0.1851 & 0.9820 & 0.9743 & 0.4221 \\
$\begin{array}{c}\text { Interaction } \\
\left.\text { (myrrh }{ }^{*} \text { time }\right)\end{array}$ & 0.6688 & 0.2219 & 0.6869 & 0.6850 & 0.5992 \\
\hline
\end{tabular}

Table 2. Means for the colors of myrrh and control as influenced by myrrh.

\begin{tabular}{cccccc}
\hline Effect & $\mathrm{L}^{*}$ & $\mathrm{a}^{*}$ & $\mathrm{~b}^{*}$ & $\mathrm{C}^{*}$ & $\mathrm{~h}^{*}$ \\
\hline Control & $95.0700^{\mathrm{a}}$ & $-0.8980^{\mathrm{a}}$ & $10.2300^{\mathrm{a}}$ & $10.2773^{\mathrm{a}}$ & $94.9080^{\mathrm{a}}$ \\
Myrrh & $93.2900^{\mathrm{b}}$ & $-0.5760^{\mathrm{b}}$ & $10.3673^{\mathrm{a}}$ & $10.3847^{\mathrm{a}}$ & $92.4947^{\mathrm{b}}$ \\
\hline
\end{tabular}

${ }^{\mathrm{ab}}$ Means not containing a common letter are significantly different $(\mathrm{p}<0.05)$.

no myrrh essential oils had the highest whiteness values in fresh cheeses and over the cheese storage period compared to cheeses containing myrrh essential oils.

\subsection{2. a* (Red-Green Axis)}

The $\mathrm{a}^{\star}$ (redness to greenness) values of the myrrh and control yogurts throughout 5 wk of storage are shown in Figure 2. The interaction effect (myrrh ${ }^{\star}$ time) and the main effect of time were not significant, but there was a significant effect for treatment myrrh (Table 1 and Table 2 ). The control yogurt $a^{\star}$ values remained steady throughout the $5 \mathrm{wk}$ whereas the myrrh yogurt values decreased from week 1 to week 5 . The $\mathrm{a}^{*}$ value of the myrrh treated yogurts showed significant decrease in the first wk, then remained stable for the remaining 4 wks. This indicated the possibility of myrrh degradation in the first week within the yogurts.

\subsection{3. $b^{*}$ (Yellow-Blue Axis)}

The $b^{*}$ (yellowness to blueness) of the myrrh and control yogurts throughout 5 wk of storage is shown in Figure 3. There was no significant difference between the control and myrrh, and the main effect of time and the interaction effect of myrrh * time was not significant (Table 1 and Table 2). Reference [5] studied the effect of essential oils extracted from myrrh on process cheese spreads and reported that the yellowish parameter $\left(\mathrm{b}^{*}\right)$ was higher than the reddish parameter $\left(\mathrm{a}^{*}\right)$ in their processed cheeses. We obtained similar results for myrrh powder suspensions in yogurt.

\subsubsection{C* (Chroma/Saturation)}

The $\mathrm{C}^{*}$ (Chroma) of the myrrh and control yogurts throughout 5 wks of storage is shown in Figure 4. There was no significant difference between control and myrrh, and the main effect of time and the interaction effect of myrrh * time was not significant (Table 1 and Table 2). 


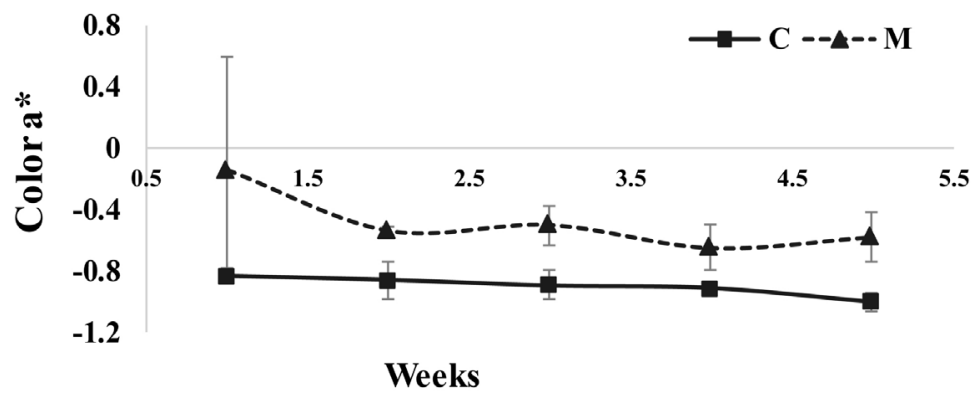

Figure 2. Measurement of $\mathrm{a}^{\star}$ color for yogurts containing myrrh and control during storage time for 5 wks.

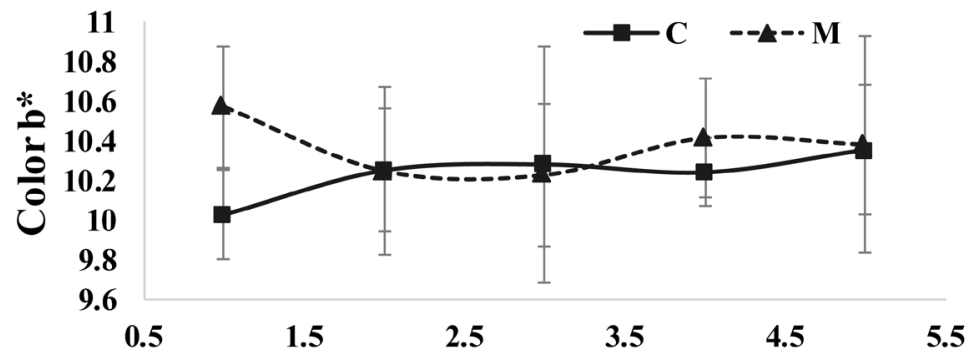

\section{Weeks}

Figure 3. Measurement of $b^{*}$ color for yogurts containing myrrh and control during storage time for $5 \mathrm{wks}$.

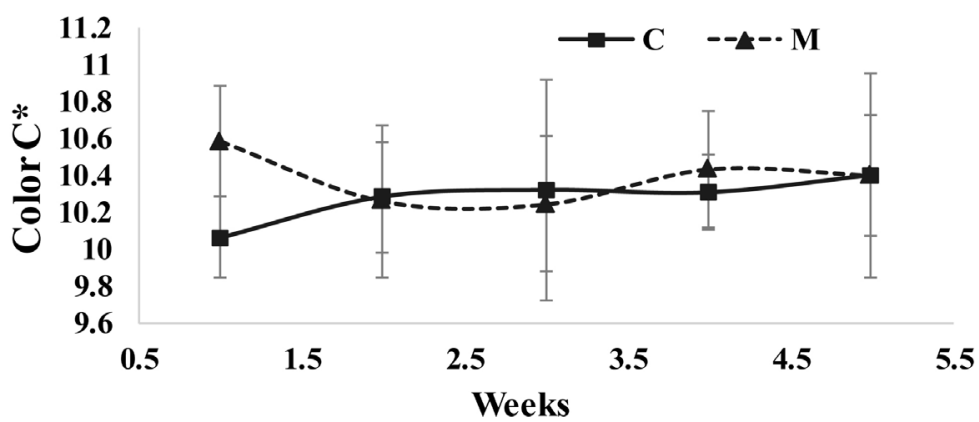

Figure 4. Measurement of $\mathrm{C}^{\star}$ color for yogurts containing myrrh and control during storage time for $5 \mathrm{wks}$.

\subsection{5. $h^{*}$ (Hue)}

The $\mathrm{h}^{*}$ (hue) of the myrrh and control yogurts throughout 5 wks of storage is shown in Figure 5. The hue for the control yogurt remained steady throughout the 5 wks whereas the hue for the myrrh yogurt increased from week 1 to week 2. The interaction effect (myrrh ${ }^{\star}$ time) and time effect were not significant, but there was a significant effect for treatment (Table 1 and Table 2).

\subsection{Apparent Viscosity}

The apparent viscosity values for myrrh and control yogurts over their shelf life are shown in Figure 6. The interaction effect (myrrh * time) was not significant. Also, the main effect of treatment myrrh and main effect of time were not significant. The 


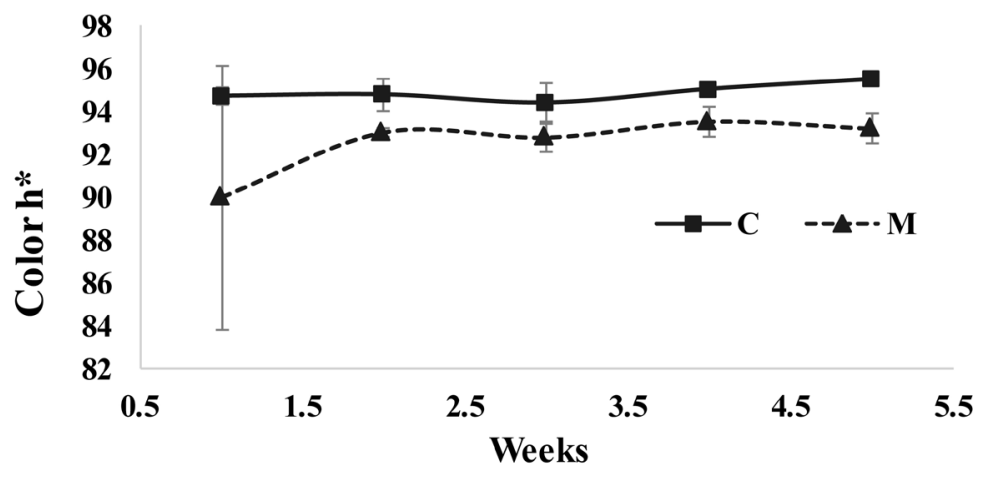

Figure 5. Measurement of $\mathrm{h}^{\star}$ color for yogurts containing myrrh and control during storage time for $5 \mathrm{wks}$.

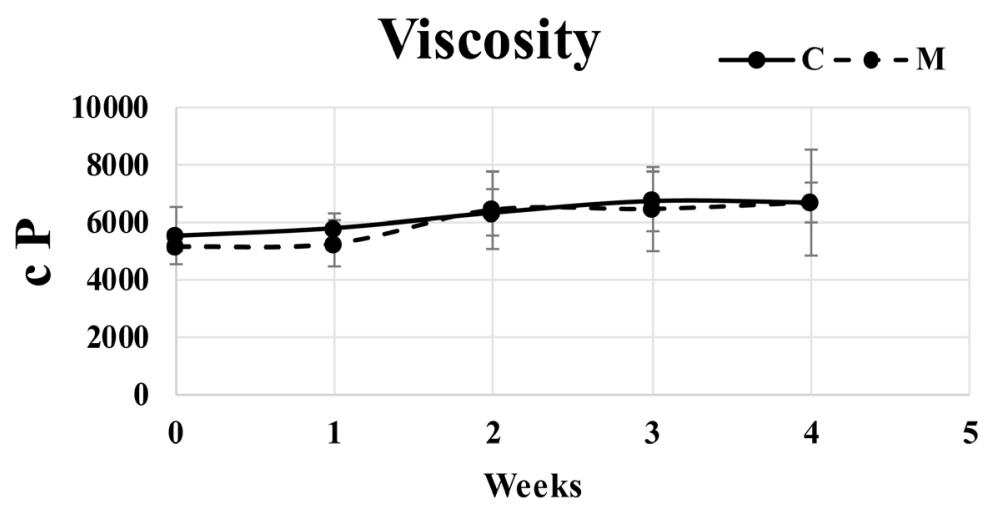

Figure 6. Apparent viscosity $(\mathrm{cP})$ of control and myrrh yogurts.

antimicrobial myrrh, did not appear to have caused any change in the casein micelle matrix structure, hence no change in the viscosity of the plain yogurts.

\section{Conclusion}

The antimicrobial myrrh influenced the color, but not the viscosity of the plain yogurts. Hence myrrh is recommended for use in a berry or fruit flavored yogurt where myrrh color contribution would be masked by the berry or fruit colors in the yogurt.

\section{Acknowledgements}

Support of the LSU AgCenter and USDA Hatch funds is appreciated.

\section{Conflicts of Interest}

The authors declare no conflicts of interest regarding the publication of this paper.

\section{References}

[1] Hanuš, L.O., Řezanka, T., Dembitsky, V.M. and Moussaieff, A. (2005) MyrrhCommiphora Chemistry. Biomedical Papers, 149, 3-28.

https://doi.org/10.5507/bp.2005.001 
[2] Lotfy, M., Badra, G., Burham, W. and Alenzi, F. (2006) Combined Use of Honey, Bee Propolis and Myrrh in Healing a Deep, Infected Wound in a Patient with Diabetes Mellitus. British Journal of Biomedical Science, 63, 171-173.

https://doi.org/10.1080/09674845.2006.11732742

[3] Kim, S.Y., Kang, D.H., Kim, J.K., Ha, Y.G., Hwang, J.Y., Kim, T. and Lee, S.H. (2011) Antimicrobial Activity of Plant Extracts against Salmonella Typhimurium, Escherichia coli O157:H7, and Listeria monocytogenes on Fresh Lettuce. Journal of Food Science, 76, M41-M46. https://doi.org/10.1111/j.1750-3841.2010.01926.x

[4] Olson, D.W. and Aryana, K.J. (2008) An Excessively High Lactobacillus acidophilus Inoculation Level in Yogurt Lowers Product Quality during Storage. LWT-Food Science and Technology, 41, 911-918. https://doi.org/10.1016/j.lwt.2007.05.017

[5] Mohamed, A.G., Abbas, H.M., Kassem, J.M., Gafour, W.A. and Attalah, A.G. (2016) Impact of Myrrh Essential Oil as a Highly Effective Antimicrobial Agent in Processed Cheese Spreads. International Journal of Dairy Science, 11, 41-51.

https://doi.org/10.3923/ijds.2016.41.51 